\title{
Guerra e sociedade: a situação militar do Rio de Janeiro no Vice-Reinado do Conde da Cunha, 1763-1767
}

\section{Christiane Mello}

\section{Introdução: As novas diretrizes militares}

A segunda metade do século XVIII é um período especialmente interessante para o estudo das forças militares. Eram imperativas as necessidades de uma intensa reorganização militar, tanto no Reino de Portugal, como, também, no Estado do Brasil, sua principal terra colonial, onde se fazia indispensável aumentar a capacidade defensiva. Tais necessidades decorriam das crescentes tensões vividas na Europa, resultantes da celebração, em agosto de 1761, do Pacto de Família, em que os vários Bourbons então reinantes se comprometiam a defender mutuamente seus Estados.

Na ocasião, embora D. José fosse casado com uma princesa Bourbon, não podiam os pactuantes esperar que Portugal aderisse ao Pacto, aliado como era da Inglaterra, então adversária da França e da Espanha na chamada Guerra dos Sete Anos, luta armada que foi travada de 1756 até 1763.

Assim, a Coroa portuguesa foi forçada a abandonar sua posição de neutralidade e a participar da fase final da Guerra dos Sete Anos. Após o estabelecimento dos Estados Ibéricos em campos opostos nesse conflito europeu, a contenda entre Portugal e Espanha logo se prolongaria avançando para as indefinidas regiōes fronteiriças sulinas. Vale notar que, como observa o historiador Fernando Novais, "ao lado das zonas de tensão entre as potências dominantes em luta pela hegemonia, França e Inglaterra, entre os países coloniais ibéricos se vão formando ao mesmo tempo outras zonas de tensão (sobretudo a região platina). Os dois tipos de conflitos correm paralelos e se inter-relacionam continuamente (...)"1.

No caso português, especificamente, o conflito com a Espanha pelos territórios às margens do rio Uruguai havia demonstrado claramente a 
precária capacidade de resistência de seu exército, sobretudo quando da invasão e conquista pelo governador de Buenos Aires, D. Pedro de Cevallos, da Colônia do Sacramento, em dezembro de 1762, bem como da vila do Rio Grande e da margem norte do canal que conectava a Lagoa dos Patos ao mar.

Não obstante assinado em fevereiro de 1763 o Tratado de Paz que havia de pôr termo à Guerra dos Sete Anos, restituindo a Portugal tudo o que fora ocupado pelos espanhóis, D. Pedro de Cevallos dispôs-se a devolver, dez meses após assinado o Tratado, apenas a Praça da Colônia, retendo o restante do território - as ilhas de São Gabriel, Martim Garcia e das Duas Irmãs e o Rio Grande de São Pedro com o seu território - e não permitindo à Colônia do Sacramento qualquer contato com o território contíguo.

Tensionavam-se, portanto, as questôes da delimitação das fronteiras das possessões portuguesas ao sul da América; a perspectiva de guerra era flagrante, e notória a necessidade de reavaliar o sistema defensivo até então utilizado. Com o intuito de aumentar a capacidade defensiva portuguesa na América, uma série de medidas foram implementadas. Podem-se citar, entre outras, a transferência, em 1763, da capital do Estado do Brasil para o Rio de Janeiro, mais próximo das regióes auríferas e mais apto a coordenar as ações militares que se prefiguravam ao Sul do Estado, o envio de regimentos militares portugueses para o Rio de Janeiro e posteriormente para o Sul.

A nova estrutura militar previa, e constantemente reiterava a todos os governadores da América portuguesa, a necessidade de cooperação entre as Capitanias do Estado do Brasil. Mereceram atenção, especialmente, as de São Paulo, Minas Gerais e Rio de Janeiro. Cabe registrar que, desde o Vice-Reinado do Conde da Cunha, a Coroa Portuguesa prescrevia como estratégia: (...) que com a uniāo de todos os trêz Governos, se possa consolidar huma força Superior (... $)^{2}$, e renovava: He, porem, necessario, que sem a menor perda de tempo, se procure em todos os trêz Governos instruir as Milicias, nos Pontos essenciais de marcharem unidos ${ }^{3}$.

Especificamente com relação à capital do Rio de Janeiro, uma particular cautela recomendava as Instruções que o Conde de Oeiras dirigiu ao Conde da Cunha, advertindo que, embora fosse de grande importância a defesa da região ao sul do Estado, 
E ainda assim no caso de marchar contra ella uma Expedição, não deve Vossa Excellencia enfraquecer o Rio de Janeiro, para se empenhar em socorrel-a de sorte que enfraqueça essa força, de que tanto necessita para deffender esse Porto, e a Cidade que a tudo deve preferir (...). ${ }^{4}$

Segundo as mesmas Instruções, a defesa daquela cidade tornava-se fundamental, posto que, além de esta capital figurar como porta principal do preciosissimo Tesouro da América ${ }^{5}$, reconhecendo a importância estratégica que há muito desempenhava a Capitania na defesa do Império português na América, admitiam: (...) o Rio de Janeiro, tem conservado e sustentado o Brasilt, acrescentando: e em que o mesmo Brasil ficaria perdido, logo que se perdesse o Rio de Janeiro ${ }^{7}$.

Em tal momento político e militarmente difícil, o Vice-Rei Conde da Cunha iniciou seu governo na Capitania do Rio de Janeiro, então a nova sede do Vice-Reino do Brasil. Nestes termos, segundo nossas pesquisas, a documentação referente àquele momento tem demonstrado que o período do Vice-Reinado do Conde da Cunha, em que se iniciava o estabelecimento das novas diretrizes régias referentes à militarização da população colonial, acabou por se tornar, pelo impacto que produziu na sociedade, um período especialmente interessante, posto que capaz de fornecer um panorama expressivo das diversas conseqüências sociais e dos efeitos da política régia em nível local.

Tornou-se possível confirmar uma de nossas questóes acerca das conexôes existentes entre a perspectiva adotada pela administração régia, que apontava para uma política de intensa militarização imposta à população civil masculina, e a crescente importância do papel das organizaçôes militares - especificamente os Corpos de Auxiliares e de Ordenanças - no seio da sociedade colonial. Temos como meta demonstrar que a realização de tais objetivos militares implicava necessariamente uma reordenação da sociedade, sob os aspectos tanto político quanto social e espacial, resultando daí as várias dimensões das dificuldades encontradas em nível local para a concretização de tal política.

\section{Obstáculos ao recrutamento militar: os privilégios}

A fim de colocar em prática as Instruções régias referentes à militarização da Capitania, o Conde da Cunha principiou por passar em revista as 
tropas já existentes. Eis, parcialmente, o resultado da avaliação da situação militar que o Vice-Rei encontrou então na Capitania e que enviou em Ofício ao Ministro e Secretário dos Negócios da Marinha e Ultramar: Em pr. lugar digo q' estão dezordenadas as tropas, o q' succede por dous motivos, o p. ${ }^{\circ}$ por falta de deceplina, e o seg. ${ }^{\circ}$ por falta de homens (... $)^{8}$. Ainda com relação ao estado das fortalezas, declarou ele: todas carecem de se lhe regular a sua defença, e de se lhe montar a Artilharia em reparos com as suas justas proporçôes (...).

Assim, ao Conde da Cunha competia, de acordo com as diretrizes político-militares que lhe haviam sido fixadas pela Coroa, tomar imediatas providências no sentido de incrementar o recrutamento de todos os homens válidos ao serviço militar, bem como de estabelecer maior regularização das tropas. Todavia, acerca do recrutamento da população para a Tropa paga, o Vice-Rei deparou com sérios obstáculos ao iniciar a tarefa que lhe fora imposta. Defrontou-se, inicialmente, com dois aspectos sociais que, embora possam ser caracterizados como típicos de uma sociedade do Antigo Regime, apresentavam-se, entretanto, segundo o Vice-Rei, em proporçóes excessivas. Eram eles a existência de uma densa rede de privilégios que em todas estas terras se tinhão permittido aos seus abitantes, era o maior motivo da sobredita impossebilidade, e por que esta importante materia, me tem feito entrar na averiguação da validade dos mesmos privilegios ${ }^{10} \mathrm{e}$, além disso, a incidência de uma enorme quantidade de jovens ordenando-se clérigos, o que, evidentemente Acresce mais a sobredita impossibilidade, outra que S. Mag.e deve prover de remedio, que he o grande numero de Frades que querem ter estas tres religióes que aqui ha de Bentos, Carmelitas e Franciscanos $\left(\right.$... ${ }^{11}$. Concluía o Vice-Rei sintetizando o quadro inicial dos obstáculos encontrados para o recrutamento de homens ativos e capazes, constatando que todos tem privilegios, ou metem-se nas Religiōes, e ordenão-se Clericos ${ }^{12}$, restando, assim, somente os homens ignuteis, são os que se podem meter nos Regimentos $^{13}$.

Diante de tais circunstâncias, o Conde Vice-Rei iniciava por tomar providências no sentido de criar condiçôes sociais propícias e necessárias à disponibilização da população masculina hábil ao serviço militar. Para atrair e dispor desses homens haveria, portanto, que interferir no âmbito dos privilégios e no do religioso, isto é, eliminar os abusos e os excessos até então 
impunemente praticados, traduzidos pelo prejuízo ao serviço real que causava o tão grande consumo de homens habeis ${ }^{14}$.

Com relação aos privilégios, denunciava o Vice-Rei ao Secretário de Estado da Marinha e do Ultramar: encontro no dos Moedeiros algumas sircunstancias dignas de se porem na prezença de S. Mag.e (.... $)^{15}$. Fundamentava sua acusação na demonstração numérica dos excessos por eles praticados, tanto ao ultrapassarem o número permitido pela ordem régia, $q^{\prime}$ só poderão ser 40 os Moedeiros do no, e não 64, como prezentem..$^{\text {te }}$ ha, sem haver ordem, ou regim. ${ }^{\text {to }} q^{\prime}$ os permita ${ }^{16}$, como também ao incluírem como privilegiados aqueles que não deveriam usufruir de tais direitos, pelo que se mostra $q^{\prime}$ este previlegio de Moedeiro, só se deve comprehender aos $q^{\prime}$ estiverem actualm. "o com exercício na caza da Moeda, e não em todos os Moedeiros do no, pois $q^{\prime}$ alguns delles nunca servirão nella ${ }^{17}$. Solicitava, então, $q^{\prime}$ o mesmo $S^{r}$ me determine, o $q^{\prime}$ devo obrar ${ }^{18}$.

\section{0 impedimento das uniões consensuais e inter-raciais}

Diante do conjunto de homens que inevitavelmente usufruíam dos privilégios, fosse por direitos de fato adquiridos, fosse por não se terem conseguido atalhar de todos os excessos praticados, a todos estes, isto é, a todos os homens que tem officios e Previlegios, para não poderem ser soldados ${ }^{19}$, determinava o Vice-Rei que tinham por dever estarem casados, uma vez que por este modo se poderá multiplicar a gente branca, e averá sold. ${ }^{o s}$ sem embaraços, e com honra (... $)^{20}$. Embora convicto dos benefícios de não se consentir que tais paisanos vivessem solteiros ou amancebados, o que se verificava na realidade social daquela Capitania, o Vice-Rei relatava justamente o contrário, pois, todos se amancebão com negras e mulatas, com estas gastão tudo o que adquirem e não se multiplica a gente branca ${ }^{21}$.

Diante de tais circunstâncias, decidiu-se o Vice-Rei Conde da Cunha, por meios muito próprios, a intervir na prática de tal costume, utilizandose, para tanto, de recursos que lhe pareceram capazes de fazer surtir os efeitos esperados. Senão, vejamos: Pelo que tenho feito publico, que os officiaes mecanicos, e Previlegiados que forem moços e não cazarem os ei de fazer Soldados. ${ }^{22}$ Interessante notar-se a associação do serviço militar com a idéia de castigo ou, minimamente, punição, e, a despeito desse fato, a franca ex- 
pectativa, senão certeza, de absoluto sucesso. Os resultados obtidos com este tipo de estratégia nos foram relatados pelo próprio Conde da Cunha:

vesse que athe o tempo prezente pedião os homens grandes dotes para cazarem, e que agora são as mulheres as que duvidão contrair matrimonio sem que se lhe segure os dotes de seus maridos, e parece me que nesta parte tenho feito hum serviço agradavel a Deus e util a S. Magestade. ${ }^{23}$

\section{A suspensão das ordenações sacerdotais}

Por outro lado, a fim de reverter outra tendência social bem acentuada na Capitania do Rio de Janeiro de então, configurada no grande consumo de homens pela religião e, naturalmente, os conseqüentes e inevitáveis obstáculos que se impunham ao recrutamento desses mesmos homens, chegando-se tal consumo ao excesso de $q .{ }^{\circ}$ se não achão nesta Cid..$^{e}$ homens moços $p .^{a}$ recruta das tropas; e havendo tantos clérigos (... ${ }^{24}$, a Coroa determinou que, em função do prejuizo q' resulta à Republica ${ }^{25}$, pelo período de dez anos, não mais se ordenassem clérigos, desautorizando expressamente que se conferissem ordenações sem que para isso houvesse nova ordem do mesmo Senhor ${ }^{26}$. Além disso, ordenou que lhe fosse enviado um censo total apresentando a relação exata do número de Sacerdotes, Choristas, Leigos e Donato $^{27}$ existentes em todos os Mosteiros, Cazas e Residencias ${ }^{28}$.

Apesar de tais determinações régias tão obviamente rigorosas, no entanto, quer-nos parecer que, inicialmente, ainda não teriam sido suficientemente capazes de sustar o excessivo número de ordenações que continuavam a ser efetivadas. Não restava ao Vice-Rei outra alternativa senão suas recorrentes queixas solicitando à Coroa as devidas providências.

\section{A defesa do Rio de Janeiro: as Tropas de cavalaria, Armamentos e Munições}

No tocante aos corpos de Auxiliares existentes na Capitania do Rio de Janeiro, o Vice-Rei, que já havia passado a sua mostra, avaliava em primeiro lugar que os Auxiliares de cavalaria he o $q^{\prime}$ pode ser $m{ }^{\text {to }}$ necess. ${ }^{\circ}$ e o mais util p. a defença, e segurança do Rio de Janr. ${ }^{.29}$; entretanto, observava logo em seguida a dezordem em q' achei este Regim. ${ }^{\text {to30 }}$. Tal ausência de or- 
dem verificada dizia respeito à forma como até então estava regulado esse Corpo, especialmente no que concerne à sua disposição espacial e aos seus respectivos oficiais, o que o tornava evidentemente inoperacional, uma vez que nenhum (oficial) assestia na freg. ${ }^{a}$ em $q^{\prime}$ tinha o seu posto, nem conhecia de vista o território em $q^{\prime}$ ella estava, pelo $q^{\prime}$ não tenha nenhum genero de exercicio, nem conhecião os seus soldados, nem estes os seus offer31. Dessa forma, procurou o Conde da Cunha tomar imediatas providências no sentido de tornar o Corpo de Auxiliares útil à defesa da Capitania: Esta dezordem a remediei logo assim neste corpo, como tão bem nos Auxiliares Infantes, fazendo trocar a todos, $p .{ }^{a} q^{\prime}$ cada hum ficasse dentro do territorio de sua comp. ${ }^{a}, o$ $q^{\prime}$ se executou com grd. ${ }^{e}$ satisfação e aprovação de todos. ${ }^{32}$

Entretanto, se o Vice-Rei conseguia, até certo ponto, remediar algumas das 'desordens' militares encontradas na Capitania do Rio de Janeiro, visando enfim dar cumprimento às determinações régias que lhe haviam sido impostas, outras dificuldades, porém, se colocavam para além de seu alcance. Ao tentar regular aqueles Corpos considerados fundamentais para a defesa da Capitania do Rio de Janeiro, os Auxiliares a cavalo, o Vice-Rei deparou com sérios obstáculos. Estes, entretanto, provinham da própria Coroa e diziam respeito ao fornecimento dos armamentos necessários para guarnecer as tropas; no caso específico dos Auxiliares e Ordenanças, vale lembrar que estes é que deveriam custear seus próprios armamentos. Assim sendo, constatava o Vice-Rei: o regim. ${ }^{\text {to }}$ dos Auxiliares de Cavallo, não estão bem armados, e não tem a onde compre estes generos; os quaes se the poderiāo vender nos mesmos Armazeis Reais, com utelid. ${ }^{e}$ grande $(. . .)^{33}$ e solicitava que a Coroa se dispusesse, com toda a brevidade possível, a enviar os armamentos necessários para guarnecer essa tropa de tão fundamental importância para a defesa da Capitania do Rio de Janeiro.

Não obstante os inúmeros apelos do Vice-Rei, a situação permanecia inalterada com relação ao envio dos armamentos e munições solicitados à Coroa. Assim sendo, o Conde da Cunha decidiu reiterar seu pedido de forma ainda mais contundente, enviando em Ofício ao Ministro e Secretário dos Negócios da Marinha e Ultramar o quadro do que entendia ser o então presente estado do Brasil. Visando chamar a atenção para as urgentes e necessárias cautelas a serem tomadas, contrapunha, em seu discurso, a riqueza do Estado do Brasil às suas péssimas condições de defesa. Adver- 
tia, relembrando à Coroa, que essa tão evidente fragilidade defensiva se agravava e acentuava ainda mais pelo fato de essa riqueza ser do conhecimento das potências européias, tornando o Estado do Brasil invejado de muitas Nações, e dezejado de todas ${ }^{34}$, o que, evidentemente, o expunha a uma permanente situação de iminente perigo. Dessa forma, avaliava a situação do Estado do Brasil de acordo com o tenso contexto no qual se encontrava, afirmando veementemente:

Delle não ha pessoa alguma q' não conheça a sua grandeza e thezouros, e q' são os maiores q' no mundo athe o prezente se tem descuberto. Este Estado do Brazil Ex. ${ }^{\mathrm{mo}}{ }^{\prime}$ S. ${ }^{\mathrm{r}} \mathrm{q}$ ' he o mais importante da R. ${ }^{\prime}$ Coroa de S. Mag. ${ }^{\mathrm{e}}(. .$.$) e$ se devia segurar $(. . .)^{35}$

\section{A defesa do Rio de Janeiro: Fortalezas e Quartéis}

Retornando à situação militar do Rio de Janeiro, constatava também suas precárias, senão trágicas, condiçōes, em decorrência de suas inúmeras carências no que concerne a todos os aspectos, mesmo os mais elementares, que pudessem dizer respeito às possibilidades de defesa da Capitania:

nem achei Fortaleza neste Porto que pudece ter este nome, nem tropas que competentes foçem a sua extenção, assim na qualidade, como no $\mathrm{n}^{\circ}$, e porque tấo bem nem armam. ${ }^{\text {tos }}$ achei para guarnecer os Auxiliares e Ordenanças, tudo pedi logo que aqui cheguei, e nem resposta tive esta materia $(. ..) .^{36}$

Vale notar, entretanto, que tais deficiências militares, às quais o ViceRei se referia, ganhavam, particularmente na Capitania do Rio de Janeiro, proporções tão intensas quanto graves, especialmente se considerando o aspecto da visibilidade à qual a cidade estava intensamente sujeita. Tal visibilidade resultava da sua peculiar situação como porto de ancoragem de diversos navios que iam em direção ao Atlântico Sul, tornando-a quase que escala obrigatória dos navios nas viagens para o extremo sul da Colônia e do continente $^{37}$, somando-se a essa situação a de exposição contínua a outras Nações - era no porto do Rio de Janeiro que se escoava o ouro que vinha das Minas Gerais, o que a tornava, inevitavelmente, uma cidade especialmente cobiçada. Dessa forma, considerava o Vice-Rei a sua estratégica e importante posição no que se referia à conservação do Estado do Brasil: 
Que a Capital deste Estado, de cuja conservação depende a existencia de Minas Geraes, hé o Rio de Janeiro; he que perdida huã vez esta Capital, se perdem consecutivamente as Minas e se pode tambem conciderar perdido todo o resto do Brazil. ${ }^{38}$

Assim, (...) pello que se ve esta cidade, que pella sua situação e porto, deve ser a cabeça do Brazil (... $)^{39}$, estando o Rio de Janeiro justamente nessa condição de cabeça do Estado do Brasil, não seria nada recomendável transparecer às outras Nações as inúmeras insuficiências militares de que padecia. O que essas mesmas Nações não pensariam acerca das outras partes desse mesmo corpo? Decorriam daí a preocupação e os esforços contínuos do Vice-Rei no sentido de tentar resolver as deficiências militares da cidade; se não conseguia concretamente saná-las, pelo menos deveria tentar manter sua aparência e sua figura militar em razoável estado, a fim de preservar não só a segurança da cidade e de seu porto, mas também a de todo o Estado, mesmo apelando para o artifício.

Significativas eram, portanto, as inquietaçôes do Vice-Rei para com a imagem da cidade perante as outras Naçôes, quando, por exemplo, abordava o estado dos quartéis, considerando: A mudança dos quarteis melitares se puder conseguir poderei fazer huma obra digna de ser vista pelas Naçôes estranhas $q^{\prime}$ aqui vem tanto a miudo; e é perciza pelo mizerável estado em $q^{\prime}$ estão os antigos (... $)^{40}$. Podemos ainda perceber semelhantes preocupaçôes quando ele se refere ao treinamento dos novos soldados, em relação ao qual tomava as devidas cautelas, não permitindo que se realizasse a aprendizagem militar destes em lugares visíveis na cidade, mas sim (...) o fazem nas Fortalezas em $q^{\prime}$ os tenho, $p .^{a} q^{\prime}$ os espanhöes não vejāo a sua desprezivel figura, pois estão nus, e descalços o q'vou remediando como posso ${ }^{41}$.

Conseguindo, de uma forma ou de outra, ocultar as graves deficiências militares da cidade perante as outras Naçôes, o Vice-Rei, entretanto, tinha diante de si a concreta realidade da capitania do Rio de Janeiro e do Estado do Brasil. Em sua avaliação, portanto, estavam desprovidos militarmente e expostos a todas as Nações não só a Capitania do Rio de Janeiro, cabeça do Estado, mas também todo o resto do Brasil. Ao concluir sua avaliação geral, o Conde da Cunha advertia especificamente a Coroa portuguesa sobre o evidente e concreto perigo em que encontravam seus domínios ao sul do Estado, considerando o seu frágil, minguado e pobre sis- 
tema defensivo diante do esperado e tão temido embate com os espanhóis na região do Prata:

Esta minha conta só se derige a por com toda a clareza na Real prezença de

S. Mag. ${ }^{e} \mathrm{q}^{\prime}$ nesta Cap. ${ }^{\text {nia }} /$ assim como nas mais do Brazil / não há tropas, nem armamentos, nem Naus, nem forças que se possão upor as grandes que os Castelhanos prezentemente tem ajuntado no R. ${ }^{\circ}$ da Prata (...). ${ }^{42}$

Ora, reportando-nos ao início do texto, poderemos perceber a objetividade e determinação dos propósitos régios no concernente à defesa de sua principal Colônia, especialmente de sua região meridional, consubstanciados no estabelecimento de maior regularização das tropas militares coloniais. Se claros e precisos eram os propósitos da Coroa, também o eram seus limites em atingir os objetivos por ela mesma traçados, por estarem, obviamente, além do que lhe permitiam seus recursos militares e financeiros.

Se, por um lado, a Coroa reconhecia a absoluta necessidade e importância de regularização das tropas coloniais para que estas pudessem estar à altura de um afrontamento militar contra as forças adversárias de Espanha, por outro, os armamentos necessários, vindos da Metrópole, dos quais a Colônia dependia totalmente para seu abastecimento, eram parcamente enviados. Em outros termos, qual poderia ser o resultado militar de tropas idealmente bem reguladas e submetidas a uma mesma impecável ordem e disciplina, se não estivessem seus combatentes devidamente armados e treinados? De tal carência padecerão as tropas coloniais durante toda a segunda metade do século XVIII.

\section{Os Povos do Sertão e o Recrutamento militar}

A urgente necessidade de militarização da sociedade colonial foi efetivamente formalizada pelas Instruçôes Régias recebidas pelos Governantes das diversas Capitanias do Estado do Brasil. Com o difícil propósito de arregimentar soldados entre aqueles que viviam "separados da sociedade civil” ${ }^{43}$, dispersos pelos sertôes, nova Carta Régia foi emitida em 22 de julho de 1766.

Com o objetivo de reorganizar a sociedade colonial, no caso específico a Capitania do Rio de Janeiro, a fim de disponibilizar para o serviço 
militar obrigatório o contingente mais destituído da população, isto é, aqueles que viviam efetivamente nos sertões, a Carta Régia expedida em 22 de julho de 1766 vinha a incidir diretamente sobre esses povos "que pelos matos, e rossas estão metidos" ${ }^{44}$, sem estabelecimento estável, ordenando que todos eles se congregassem em povoaçôes e se reduzissem à sociedade civil. Assim, determinava:

(...) todos os homens, que nos ditos Certoens se achassem vagabundos, ou em citios volantes, fossem logo obrigados a escolher lugares acomodados para viverem juntos em povoacçoens, que pelo menos tivessem sincoenta fogos para sima, com Juiz Ordinario, Vereadores e Procurador do Concelho, repartindo-se entre elles, com justa proporção, as terras adjacentes. (...) E isto debaixo de pena, de que aquelles (...) que não aparecerem para se congregarem (...) serão tratados como Inimigos Comuns, e como taes punidos com a severidade das Leis $(. . .)^{45}$.

Esta Ordem ilustra bem a estratégia da Coroa no sentido de disponibilizar para o serviço militar todos os homens que se encontrassem fora das comunidades e que, de alguma forma, causassem transtornos à população, isto é, todos aqueles classificados como "vadios e fasinorozos" ${ }^{46}$, bem como os trabalhadores itinerantes. A fim de se poder, com maior facilidade, dispor militarmente desse grande contingente que se encontrava então disperso pelos sertôes, para bem integrá-los aos corpos militares, havia, primeiro, que dispô-los em lugares adequados e convenientes, isto é, circunscrevê-los territorialmente.

Entretanto, para a consecução do objetivo final acima descrito, outras questôes havia ainda a serem consideradas, posto que a distância que separava esses elementos da sociedade civil não era apenas uma questão de ordem física ou espacial, assim como a entendia a Coroa, não sendo, portanto, apenas o deslocamento físico por ela proposto a solução mais viável para se atingirem os objetivos em mira. Outras distâncias se impunham, tão ou mais concretas que as físicas: as sociais, enquanto motivadoras da partida de tão numerosos contingentes para os sertôes e suficientemente fortes para mantê-los nessa região, estranhos ao alcance da ordem social.

De tais outras distâncias, ainda, nos dá conta o Vice-Rei Conde da Cunha, que, além de demonstrar a impossibilidade prática da plena implementação das medidas expressas na Carta Régia de 22 de julho de 1766, 
e a fim de apresentar soluções para as questões sobre as quais a mesma se debruçava, sugeria outras alternativas consideradas por ele mais adequadas à realidade social da Capitania do Rio de Janeiro. Dessa forma, iniciava sua argumentação com uma afirmação bastante pessimista acerca dos resultados esperados das medidas contidas na Carta Régia: "as dificuldades que a sua execução ha de ter, me parecem infaliveis" ${ }^{47}$.

\section{Vagabundos e Trabalhadores itinerantes: os Projetos de defesa do Vice-Rei Conde da Cunha}

Às classificações genéricas contidas na Carta Régia de 1766 a respeito desses povos, o Conde da Cunha respondia, por sua vez, expondo detalhadamente as condições e as distinções existentes entre aqueles que viviam pelos sertôes. Inicialmente, classificava-os em dois grandes grupos básicos: o primeiro, composto pelas muitas famílias que há nesta Capitania sem caza, nem domicilio (...) são todas estas gentes de pobreza tão conhecida, que se não pode duvidar da sua impossibilidade ${ }^{48}$, e o segundo, formado pelos socialmente marginais, aqueles denominados os vadios, os facinorosos, e vagabun$d o s^{49}$. Procedia, em seguida, à explicação detalhada acerca das diversas especificidades das condições sociais desses diferentes povos e, em face dessas condições e diferenças, as medidas por ele consideradas mais apropriadas para a solução das questões levantadas. Vejamos, portanto, as três maiores dificuldades encontradas pelo Vice-Rei a fim de, como determinava a Carta Régia de 22 de julho de 1766, estabelecer em povoações permanentes esses povos, que viviam dispersos pelos sertóes:

A primeira he: Que os vadios, os facinorozos, e vagabundos, que estão nos Certoens, e em citios volantes, a necessidade os obriga a viverem fora da sociedade civil; porque huns por dividas mui consideraveis, outros por crimes gravissimos, lhe não hé possivel virem buscar a comunicação das gentes, pois os da condição dos primeiros, hirião logo para as Cadeias aonde acabarião ali as suas vidas (...) e os da segunda as perderião logo na Forca (...)..$^{50}$

Vê-se que a aplicação da pena de prisão no Rio de Janeiro tornava-se um grande problema, uma vez que a cidade não se encontrava preparada para comportar em sua cadeia o número de indivíduos que deveriam estar presos: 
A cadeia desta cid. ${ }^{\text {e }}$ he tão pequena $\mathrm{q}^{\prime}$ com grd. ${ }^{\mathrm{e}}$ aperto e discomando dos prezos, só poderã recolher athé 150 , e porq' prezentem. ${ }^{\text {te }}$ tem 253 , se faz percizo $q^{\prime}$, ou se acrescente a caza da prizão ou se não prendão os $q^{\prime}$ deliquirem daqui em diante, por não haver onde se recolhão (...). ${ }^{51}$

A fim de remediar tal impasse, evitando-se as despesas que acarretariam as obras para o aumento da cadeia e atendo-se ao propósito régio de arregimentação de soldados para as tropas, sobretudo as destinadas ao Sul, sugeria o Vice-Rei a D. José “q’ todos os prezos, q' estiverem sentenciados, e p. ${ }^{a}$ o diante se sentenciarem com degredos, e condenações pecuniárias" pudessem ser enviados "p. a Angola, S. Cath. a, e outros destritos" ${ }^{\text {a }}$. Entretanto, declarava o Conde da Cunha que não o pode fazer porque havia se deparado com a oposição do Tribunal da Relação, que insistia em afirmar que tal proposta não poderia ser efetivada “sem q' os delinqüientes paguem as condenações com q' forão sentenciados, $\mathrm{p} .{ }^{\mathrm{a}}$ as despezas do mesmo Tribunal" 53 . Demonstrando a falta de coerência na posição tomada pela Relação, contrapõe o Vice-Rei “q' não tendo estes infelices, como he certo, q' não tem bens alguns com q' paguem estas quantias, se tem perpetuado na cadeia, sem esperança algu'a de poderem sahir della" ${ }^{4}$.

No entanto, sem a intenção de isentar os delinqüentes de suas respectivas dívidas de condenação para com a Relação, sugeria o Conde da Cunha que, antes destes serem enviados para as expedições militares, se celebrasse um "termo, de as pagarem, se melhorarem de fortuna" 55 . Assim, pela proposta feita, resolver-se-iam alguns problemas, entre os quais: economizar-se-ia nos gastos das obras da cadeia, aliviar-se-ia o excesso de presos existentes na incipiente prisão, utilizar-se-iam daqueles detidos para engrossar as fileiras, sempre tão desfalcadas de efetivos, na defesa das praças ao sul, e ainda, apresentar-se-ia uma esperança de pagamento destes à Relação, o que certamente não aconteceria se simplesmente permanecessem presos. Diante de tão favoráveis argumentos, D. José decide-se por aprovar a proposta do Conde da Cunha ${ }^{56}$. Assim, saíam "os muitos creminozos" e "delinqüentes" 57 da cadeia direto para as tropas, assim "aumentando considerável. ${ }^{\text {te }}$ em num. ${ }^{\circ}$ de soldados" ${ }^{58}$. Vale destacar, entretanto, que tais propostas só resultariam de fato positivas, do ponto de vista da autoridade régia, se não se considerasse, evidentemente, a eterna ameaça que pairava sobre a composição de todas as tropas coloniais, isto é, a possibilidade de 
deserção, ameaça essa tão presente quanto recorrente na história militar colonial. E em se considerando, ainda, aqueles homens especialmente habituados a viver nos imensos sertôes existentes naquele vasto território, quer nos parecer que sua deserção poderia ser inevitável.

Se, em conseqüência dos graves delitos por eles praticados, não via o Vice-Rei quaisquer possibilidades de integrar os vadios na sociedade civil, outra, entretanto, não era a perspectiva, nem mais otimista, ainda que por motivo diverso, com relação às famílias de conhecida miséria que viviam pelos sertões. A análise do Vice-Rei relatava que não tem, nem huma só camiza, nem couza alguma com que se cubrão, pelo que, esta mizeria os obriga, a que se escondão pelos matos, e vivão como brutos (... $)^{59}$ e que, portanto, a fim de introduzi-los na sociedade civil, a primeira providência a tomar seria vesti-los ao menos com duas camizas, e algumas baratas drogas para de todo se cobrirem (... $)^{60}$. Constatava ele, porém, a improbabilidade de solução dessa situação, em razão de suas óbvias implicações financeiras. Outras situações, de ainda mais desafiadora solução, se apresentavam:

A segunda consiste em que, a falta que há de cazas nos povoados para se poderem estabelecer e recolher estas gentes que pelos matos e rossas estão metidos, e dispersas porque as não há de aluguel; e quando as houvesse serião (como são) muito caras (...). "A terceira, e ultima hé para mim a mais dificultoza; por que ordenando $S$. Magestade, que com estas gentes, que aos povoados se recolherem, se repartão com justiça, e proporção as terras adjacentes, não sei o como isto se possa praticar, porque era precizo, que houvesse terrenos, que fossem dos proprios de $S$. Magestade, e isto hé o que já não há no Rio de Janeiro, (....). ${ }^{61}$

Entretanto, apesar das dificuldades acima expostas, em termos de terras ou de habitações disponíveis, e que se constituíam basicamente nos obstáculos que a própria cidade apresentava, traduzidos pela ausência de espaço para acolher aqueles necessários e cobiçados contingentes, o Conde da Cunha formulou sua proposta, que, mister que se diga, seria, a partir de então, recorrente em toda a sua correspondência com a Coroa. Ei-la, sucintamente citada:

A providencia, que pode haver para que todos estes infelises possão ter terras de que se utilizem, e vivão em povoados civilmente he o de se lhe darem 
alguns daquellas, que estão incultas, e abandonadas de todo por seos donos Cesmeros (...) Pela que nas margens desta grande Bahia, hé que seria conveniente, que as novas Villas se criassem e erigissem em partes comodas assim para a sua subsistência, como para a comunicação com os outros povos (...). ${ }^{62}$

Percebe-se, pelas subseqüentes cartas do Vice-Rei, que, com o tempo, a idéia acima proposta se converteu em um projeto mais denso e elaborado do Conde da Cunha para a Capitania do Rio de Janeiro, vindo a ser defendido como o mais adequado para a situação da Capitania e a solução mais apropriada para a resolução de alguns dos inúmeros problemas que a assolavam - pelo menos aqueles que diziam respeito à diminuição, senão erradicação, da imensa pobreza vivida por grande parte da população de sua Capitania. $\mathrm{O}$ projeto indicava a disposição destes povos às margens da Baía de Guanabara, para sua utilização não somente na muito relevante missão de defesa da costa marítima, tão despovoada quanto vulnerável aos repentinos ataques dos inimigos, bem como solucionando, de uma só feita, através de sua ordenação em Terços de Auxiliares, as sérias dificuldades encontradas em decorrência das dilatadas distâncias existentes entre os distritos da Capitania do Rio de Janeiro.

\section{Rio de Janeiro e a Colônia do Sacramento}

Independentemente dos projetos de defesa que tinha o Vice-Rei Conde da Cunha para a Capitania do Rio de Janeiro, talvez de tão difícil execução quanto aqueles propostos pela Coroa, apresentava-se a urgente necessidade de se levantarem mais Tropas na Capitania, tanto para sua própria defesa quanto para o envio às fronteiras sulinas. Nesse sentido, havia o Vice-Rei que se adaptar às contingências locais e formar as Tropas ou Terços em função das possibilidades que se apresentassem na Capitania. Sua primeira preocupação fora a de compor os Terços de Auxiliares; entretanto, advertia o Vice-Rei, em ofício a Francisco Xavier Mendonça de Furtado, que o número de praças, isto é, dos soldados que comporiam cada Terço, inevitavelmente sofreria variações, posto que os destrictos, que se hão de formar [os Terços], assim como também as Freguezias, que cada hum delles em si comprehende (...) são muito mais populozas que outras ${ }^{63}$. Dessa forma, no concernente ao número de soldados em todos os Terços de Au- 
xiliares, tais Terços não estariam integralmente concordantes com a ordem régia de uniformidade.

Já acerca das Ordenanças que deveriam ser levantadas na Capitania, o Vice-Rei afirma que, sem antes formar os de Auxiliares, não poderia ter a idéia exata de quantos haveriam de dispor a Capitania: assim, depois de ter formado os primeiros Corpos dos Auxiliares, conhecerei quantos há de haver de Ordenanças ${ }^{64}$. Nesse sentido, deve-se considerar que a prioridade dada pelo Conde da Cunha à composição dos Terços de Auxiliares em relação aos de Ordenanças resulta do fato de que aqueles, além de serem passíveis de poderem ser enviados às regiōes sulinas, podiam, também, substituir na defesa da Capitania a tropa paga, cuja maioria de efetivos encontrava-se nas fronteiras sulinas. Assim, afirmava o Vice-Rei a respeito das tropas pagas e dos Auxiliares que esta capitania tem só tres regimentos [pagos] e que alem de se acharem deminutos estão devididos nos destacam. ${ }^{o s}$ que tenho na Collonia, St. ${ }^{a}$ Catharina, e Rio Grande, e que por esta cauza fazem os Auxiliares $m .{ }^{\text {ta }}$ parte do serviço que só aos pagos competia ${ }^{65}$.

A despeito do constante envio de soldados pagos para as praças do sul, parecia nunca ser o suficiente para completar, sequer minimamente, $o$ número de soldados necessários para as tropas ali alocadas, sendo sua falta invariavelmente considerável e muito preocupante. A permanente insuficiência de soldados resultava mormente do alto índice de deserção sofrido pelas tropas ali posicionadas. Assim, por exemplo, acerca da Colônia do Sacramento, verificava o Vice-Rei que a continua dezerção dos soldados q'a guarnecem he excessiva ${ }^{66}$.

Assim, a intensa deserção verificada naquelas praças, e suas insaciáveis demandas por mais soldados, repercutiam negativamente nas Capitanias do Estado do Brasil, especialmente as do centro-sul - Rio de Janeiro, São Paulo e Minas Gerais -, enfraquecendo-as consideravelmente de seus efetivos militares. $\mathrm{Na}$ Capitania do Rio de Janeiro, alarmante era a falta de soldados pagos, o que, conseqüentemente, tornava a ação de recrutamento uma constante. O nível de insustentabilidade atingido por essa situação, representado pelo diminuto número de soldados existentes no Rio de Janeiro e o infatigável trabalho de recrutamento, levava o Vice-Rei a declarar

que os [soldados] que conservo nesta Capitania são já tão poucos que não tem, nem hum só dia de descanço, trabalho este, que se faz quazi impossivel 
de se puder continuar (...) sendo que tudo he pouco para se puder guarnecer a Colonia, Rio Grande e Santa Catharina. ${ }^{67}$

Com o intuito de aliviar os excessivos encargos militares sofridos pela Capitania do Rio de Janeiro e visando, ainda, atender aos constantes apelos do Vice-Rei por efetivos outros que não fossem os cariocas, porq'são moles, e faltos de valor ${ }^{68}$, nem tampouco os que são do Brasil, não tem prestimo, pela sua excessiva perguiça, e negação $p^{a}$ a vida militar ${ }^{69}$, a Coroa decide-se a enviar para a capital homens recrutados na Ilha de São Miguel. A 9 de agosto de 1766, chegava ao porto da cidade do Rio de Janeiro a recruta de duzentos homens, a qual avaliava entusiasmado o Conde da Cunha que, por serem todos voluntarios, de boas figuras, e desembaraço, hé própria para o ministério a que vem destinada. Informava, ainda, à Coroa que todos elles me segurão, que muitos mais queriāo vir por sua livre vontade e concluía considerando que seria muito util haver outra semelhante recruta ${ }^{70}$.

\section{Os baixos soldos e o ouro das Minas Gerais}

Não somente continuavam alarmantes as notícias de deserção nas praças do sul, mas, inclusive e continuamente, muitos dos que desertavam passavam aos arraiais inimigos. Desde o início de seu governo, a fim de aplacar tão inúmeras deserções, o Vice-Rei Conde da Cunha entrevia apenas uma solução: só o aumento do soldo podera ter mão nesta gente, q’ por falta de meios $p .{ }^{a}$ puder viver, procura melhorar de fortuna ainda q' seja em terra alheia ${ }^{71}$.

Um ano após o Vice-Rei ter advertido acerca do excessivo número de deserçôes lá verificadas, a Coroa se decide a aumentar o soldo dos combatentes da praça da Colônia do Sacramento. Em carta, o Conde da Cunha agradece o reconhecimento da Coroa e aponta para suas eventuais conseqüências favoráveis, ressalvando, entretanto, que estas somente viriam a se verificar após o efetivo aumento dos soldos das tropas por sua $R .^{l}$ grandeza, mandando acrescentar os soldos aos melitares da praça da Col. ${ }^{a}, q^{\prime}$ com este beneficio ldepois de ser praticadol me parece, q' os castelhanos não tornarão a entrar nella ${ }^{72}$.

Se a questão do soldo, já irrisório, quando não de sua total ausência, recebido pelos soldados nas fronteiras, os levava a tentar melhorar de fortu- 
na (...) em terra alheia ${ }^{73}$, aqueles menos próximos da terra alheia fugiam, pelo mesmo motivo, para outras terras, as das Minas que, mesmo não sendo alheia, tornava-se, ainda assim, muito perigosa, pela atração que exercia sobre um imenso número de soldados que, constantemente, desertavam em busca de seu tão cobiçado ouro.

Portanto, da conjunção entre o baixo, ou nenhum, soldo e o ouro das Minas, o resultado, óbvio e inevitável, era a maciça deserção dos soldados. Assim, um ano após a chegada da recruta da Ilha de São Miguel, o ViceRei percebia, desolado, os reais objetivos daqueles voluntários de tão boas figuras, e desembaraço e tão próprios para o ministério a que vem destinado ${ }^{74}$, qual seja, que todos estes homens que com tanto gosto, e por sua livre vontade vem das Ilhas para o Rio de Janeiro; não he porque queirão servir a S.Mag. ${ }^{\text {, }}$ mas sim, e só com o designo de se irem meter nas Minas ${ }^{75}$. E, segundo o Conde da Cunha, todos os fazem por dous motivos; o primeiro he o não ser possivel sustentarem-se com o soldo que S.Mag. Ihe dá; e o segundo he saberem a abundância que naquelas terras [de Minas] há ${ }^{76}$. Além do que, não somente os soldados provenientes da Ilha, como os desse Reino dezertão prezentemente todos os dias para Minas ${ }^{77}$.

\section{A Deserção e a Amplitude do Estado do Brasil}

Ao Conde da Cunha parecia a deserção uma insolúvel irregularidade, a cujas razóes, ainda, somava-se uma outra, a atuar peremptoriamente: a vastidão incomprheensivel deste Estado ${ }^{78}$. Operando amplamente como fator de reforço e estímulo à deserção, sua ampla vastidão garantia a proteção e a imunidade dos muitos que a praticavam, de tal modo que não he possivel achallos para os castigar, e trazer aos seus corpos: São tantos os caminhos, que prezentemente ha, para aquella capitania [Minas Gerais], e a de S. Paulo, e por povoados, que já não cabe no possivel que este danno se evite com guardas $^{79}$. Não obstante serem os soldados desertores, e, quando encontrados, enviados à prisão e sentenciados com os devidos castigos, parecia, ainda assim, que punição nenhuma seria capaz de surtir qualquer efeito corretivo sobre aqueles homens, pois, nem assim tem emenda. Pelo que me persuado, que o castigo lhes não faz termos, e que antes querem sugeitar-se à elle, do que a regularidade Militar $^{80}$. O serviço militar para esses homens representava 
uma penalidade de tão grandes proporções que dificilmente os castigos seriam capazes de intimidá-los, e muito menos de evitarem suas constantes fugas das fileiras.

Quanto à questão dos recrutados fora do Estado do Brasil, como, por exemplo, os da Ilha de São Miguel, passou a considerar o Conde da Cunha, devido à excessiva deserção verificada entre eles, inviável sua vinda. A fim de solucionar o tão grave impasse da falta de soldados, avaliava o ViceRei que estes deveriam ser recrutados entre os naturais da cidade:

só os soldados naturais do Rio de Janeiro, podem viver nelle /ainda que com excessiva mizeria/ com os soldos que S.Magestade lhe manda dar, e que para assim os haver, seria precizo que se não pudessem meter frade nem ordenar clericos. ${ }^{81}$

Ora, encontrava-se, novamente, o Conde da Cunha diante do mesmo obstáculo do início de seu governo - os privilégios - obstáculo não menos difícil de superar do que o anterior - a deserção. Deve-se considerar que, efetivamente, só eram recrutados para soldados das tropas pagas aqueles que, como já visto, não se conseguiam eximir pela via dos privilégios, fossem eles provenientes da Santíssima Trindade, da Bula da Cruzada, dos Familiares do Santo Ofício, dos Moedeiros ou, sobretudo, das Ordens Religiosas responsáveis por ordenar um grande número de jovens que, se assim não fosse, estariam habilitados ao serviço militar. Em outros termos, referimo-nos não somente aos direitos de privilégios, mas, mais especificamente, ao uso alargado destes, indevida e fartamente utilizado na Capitania do Rio de Janeiro, e que se constituía nada menos que um dos magnos problemas concernentes ao recrutamento militar.

\section{Sertão-Prisão-Tropa-Sertão}

Sendo assim, os que realmente se tornavam passíveis de serem recrutados para soldados eram mormente os vagabundos e os trabalhadores itinerantes, que não logravam obter a proteção de qualquer rede de isenção, em suma, todos aqueles que, por inexcelência, viviam fora de qualquer sociedade civil.

Deste modo, pode-se verificar que, embora árdua e de difícil execução, tornava-se imperativo, uma vez concluídos os recrutamentos nas vi- 
las, cidades e em suas respectivas cadeias, adentrar "nas estradas dezertas, e sertôes" 82 da Capitania, posto que era ali que se arregimentava o maior número dos efetivos para compor as tropas coloniais. Apreciemos, parcialmente, o relato do capitão de Ordenanças do distrito de Itaboraí, que, a fim de recrutar "gente para sold. ${ }^{\text {os }}$ da Infant. ${ }^{a}$ da mesma cid. ${ }^{e}$ [do Rio de Janeiro]"83, fora incumbido de uma diligência de "evidente perigo" ${ }^{84}$, qual fosse o de penetrar pelos sertóes, posto que era o lugar para onde iam "os que fogem para não serem prezos p. ${ }^{\text {a }}$ soldados, e se animão a rezistir a toda a qualid. ' de pessoas q' os procurão" ${ }^{\prime 5}$.

Ressalte-se que, para todos aqueles que vivessem dispersos pelos sertôes ou matos e que não se congregassem em povoaçôes civis, as determinações da Carta Régia de 22 de julho de $1766^{86}$, acima analisada, eram extremamente severas em suas puniçôes. Prescreviam-se, ali, as medidas acerca dos meios e das penalidades que sofreriam todos os que se encontrassem nos sitios volantes: os trabalhadores itinerantes, bem como os vadios eventualmente encontrados nos caminhos e matos ${ }^{87}$, a quem determinava fossem indiscriminadamente tratados como salteadores de caminhos, e inimigos comuns, e como tais punidos com a severidade das leis $^{88}$. Para a exata consecução de tal objetivo, a Coroa concedia poder de polícia a particulares, outorgando a roceiros, rancheiros e tropas de bandeiras toda a necessária autoridade para prenderem, e remeterem às cadeias públicas das comarcas que estiverem mais vizinhas, todos os homens que acharem dispersos ${ }^{89}$.

Ora, por serem grupos estrategicamente posicionados nos sertôes, julgou a Coroa poder contar com a total e irrestrita colaboração dos roceiros, rancheiros e tropas de bandeiras, o que em muito facilitaria a tarefa de reconhecimento e de perseguição daqueles homens que, dispersos pelas brenhas, viviam sob a mira das ordens régias, bem como os que fugiam ao risco de recrutamento, e os desertores. Dispondo da autoridade pública ${ }^{90}$ concedida pela Coroa, aqueles grupos, em última análise, poderiam prestar-se à difícil tarefa de arregimentação, dentre aquele contingente que se encontrava pelos sertões, de homens para soldados.

Entretanto, complexo era o mundo colonial. Se, por um lado, nem sempre a autoridade pública confiada àqueles grupos resultava de fato nos propósitos previstos pela Coroa, acabava, por vezes, gerando o contrário: o acoutamento de homens que deveriam tornar-se soldados. Por outro, se 
de fato remetidos à prisão, e, em seguida, às tropas, nada tampouco garantiria sua permanência naquelas, muito pelo contrário.

Dessa forma, vale observar que um interminável círculo vicioso se produzia, posto que, uma vez encontrados nos sertôes, levados à cadeia e, em seguida, remetidos para as tropas, esses homens, militarizados à força, voltavam fatalmente a escapar para os amplos espaços do sertão. Tal ocorrência fazia com que especialmente as tropas, tanto de auxiliares como regulares, no que concerne a seus efetivos, fossem tão efêmeras, e se dissolvessem tanto quanto se movimentassem, alimentando-se contínua e inexoravelmente desse, e nesse inacabável movimento vicioso pelo qual os homens militarmente úteis se viam enredados: sertão-prisão-tropa-sertão.

O que nos impõe destacar é que, em decorrência da forte inflexão quantitativa (número de tropas) e qualitativa (ordenação das tropas) da nova estratégia militar, imposta durante a segunda metade do século XVIII, a resistência popular se acentuou, atingindo seu ápice em decorrência da intensificação do recrutamento, bem como da exigência de uma maior regularização e disciplinarização das tropas coloniais. A realização de tais objetivos militares implicava necessariamente uma reordenação da sociedade, sob os aspectos tanto político quanto social e espacial, resultando daí as várias dimensões das dificuldades encontradas em nível local para a concretização de tal política.

No período estudado, o principal fundamento justificador das freqüentes intervençōes legislativas da Coroa efetivadas na sociedade civil revestia-se, essencialmente, das questôes que diziam respeito à esfera militar, tornandose claramente perceptível o contínuo esforço no sentido do alargamento e da ampliação do espaço militar no interior da sociedade civil.

Entretanto, deve-se ressaltar que, a despeito da firmeza dos propósitos régios no que concerne à defesa de sua principal Colônia, especialmente a Capitania do Rio de Janeiro, a sua situação militar era muito frágil, tanto antes como depois do vice-reinado do Conde da Cunha. Assim, se claros e precisos eram os propósitos da Coroa, também o eram seus limites em atingir os objetivos por ela mesma traçados, por estarem, obviamente, além do que lhe permitiam seus recursos militares e financeiros.

Em termos gerais, pode-se afirmar que, a condição militar do Rio de Janeiro era precária, senão trágica, em decorrência de suas inúmeras carên- 
cias no que concerne a todos os aspectos, mesmo os mais elementares, que pudessem dizer respeito às possibilidades de defesa da Capitania. As deficiências militares da Capitania abrangiam as fortalezas que, em sua maioria, permaneciam necessitadas de reparo nas muralhas e nas peças de artilharia, a falta constante de armamentos e munições para guarnecer as tropas, os quartéis em miserável estado e o recrutamento com suas resistências, sejam elas pela utilização de privilégios, fugas ou deserções e suas densas redes de proteção que tanto enfraqueciam as tropas. De tais carências padecerá a Capitania do Rio de Janeiro durante toda a segunda metade do século XVIII.

\section{Fontes e Bibliografia}

Arquivo Histórico Ultramarino (AHU), Rio de Janeiro (RJ), Caixa (Cx.) 77, Documento (Doc.) 77. "Ofício do Vice-Rei Conde da Cunha para Francisco Xavier de Mendonça Furtado. Rio de Janeiro, 16/6/1764”,

AHU, RJ, Cx. 78, Doc. 4. "Ofício do Vice-Rei Conde da Cunha para Francisco Xavier de Mendonça Furtado. RJ, 10/7/1764”

AHU, Cx. 77, RJ, Doc. 77. "Ofício do Vice-Rei Conde da Cunha para Francisco Xavier de Mendonça Furtado, RJ. 16/6/1764”,.

AHU, RJ, Cx. 79, Doc. 24. "Ofício do Vice-Rei Conde da Cunha para Francisco Xavier de Mendonça Furtado. RJ, 23/9/1764",

AHU, RJ, Cx. 80, Doc. 32. "Ofício do Vice-Rei Conde da Cunha para Francisco Xavier de Mendonça Furtado. RJ, 29/1/1765”

AHU, RJ, Cx. 86, Doc. 60. "Ofício do Bispo do Rio de Janeiro, Frei Antonio do Desterro, para Francisco Xavier de Mendonça Furtado. RJ, 22/12/1766”, AHU, RJ, Cx. 78, Doc. 21. "Ofício do Provincial da Ordem de N. S. do Monte do Carmo do Rio de Janeiro, Frei Manoel Angelo, para Francisco Xavier de Mendonça Furtado. RJ, 20/8/1764",

AHU, RJ, Cx. 77, Doc. 59.Carta do Vice-Rei Conde da Cunha ao Rei D. José I. RJ, 1/6/1764", .

AHU, RJ, Cx. 77, Doc. 86.Carta do Vice-Rei Conde da Cunha ao Rei D. José I. RJ, 18/6/1764"

AHU, RJ, Cx. 90, Doc. 76. "Minuta escrita pelo Vice-Rei Conde da Cunha. RJ, 1767 ", 
AHU, RJ, Cx. 83, Doc. 1. "Ofício do Vice-Rei Conde da Cunha para Francisco Xavier de Mendonça Furtado RJ, 3/11/1765”

AHU, RJ, Cx. 87, Doc. 78. "Ofício do Vice-Rei Conde da Cunha para Francisco Xavier de Mendonça Furtado. RJ, 24/3/1767”

AHU, RJ, Cx. 81, Doc. 55. "Ofício do Vice-Rei Conde da Cunha para Francisco Xavier de Mendonça Furtado. RJ, 29/6/1765”

Arquivo Nacional do Rio de Janeiro, Códice 73, volume 2, página 14. "Edital, em que fez. Ordenar S.Mage. que todos os homens que se acharem vagabundos nos Sertoens, ou em Sítios Volantes desta Capitania, sejão logo obrigados a viverem em Povoações civis, Ajuda, 22/7/1766."

AHU, RJ, Cx. 77, Doc. 58. "Carta do Vice-Rei Conde da Cunha ao Rei D. José I. RJ, 1/6/1764."

AHU, Códice 230, p.131. "D. José para o Conde da Cunha, Lisboa, 15/12/1764”, AHU, RJ, Cx.81, doc.45. "Ofício do Vice-Rei a Francisco Xavier Mendonça de Furtado, RJ, 22/6/1765”

AHU, RJ, Cx. 87, Doc. 37. "Ofício do Vice-Rei a Francisco Xavier de Mendonça Furtado. RJ, 23/2/1767."

AHU, RJ, Cx.77, doc.38. "Ofício do Conde da Cunha para Francisco Xavier Mendonça Furtado, R.J., 15/3/1764”

AHU, RJ, Cx.77, doc. 25 "Ofício do Conde da Cunha para Francisco Xavier Mendonça Furtado, R.J., 29/2/1764”

AHU RJ, Cx.82, doc.16. "Ofício do Conde da Cunha para Francisco Xavier Mendonça Furtado, R.J., 4/7/1765”

AHU, RJ, Cx.79, doc.11. "Ofício do Conde da Cunha para Francisco Xavier Mendonça Furtado, R.J., 17/9/1764”

AHU, RJ, Cx.86, doc.11. "Ofício do Conde da Cunha para Francisco Xavier Mendonça Furtado, R.J., 6/9/1766”,

AHU, RJ, Cx.90, doc.2. "Ofício do Conde da Cunha para Francisco Xavier Mendonça Furtado, R.J., 1/11/1767”,

AHU, RJ, Cx.89, doc.60. "Ofício do Conde da Cunha para Francisco Xavier Mendonça Furtado, R.J., 9/9/1767”

AHU, RJ, Cx.90, doc.2. "Ofício do Conde da Cunha para Francisco Xavier Mendonça Furtado, R.J., 1/11/1767” 
AHU, RJ, Cx. 91, doc. 67. "Conde de Azambuja para Francisco Xavier Mendonça Furtado, R. J., 18/5/1768”.

AHU, Cx. 88, Doc. 66. "Ofício do Vice-Rei Conde da Cunha para Francisco Xavier de Mendonça Furtado. R. J, 27/7/1767”.

AHU, RJ, Avulsos, Cx. 80, doc. 75. "Requerimento do Capitão de Ordenança à pé de Itaboraí a D. José, R. J, 27/2/1765”.

\section{Bibliografia}

BELLOTTO, Heloísa Liberalli. Autoridade e Conflito no Brasil Colonial: O Governo do Morgado de Mateus em São Paulo (1765-1775). São Paulo: Conselho Estadual de Artes e Ciências Humanas, 1979.

MENDONÇA, Marcos Carneiro de. Século XVIII-Século Pombalino do Brasil. Rio de Janeiro: Xerox do Brasil S.A., 1989.

SANTOS, Corcino Medeiros dos. O Rio de Janeiro e a Conjuntura Atlântica. Rio de Janeiro: Ed. Expressão e Cultura, 1993.

\section{Notas}

${ }^{1}$ Novais, Fernando. Portugal e Brasil na Crise do Antigo Sistema Colonial (1777-1808), S.P: Hucitec, 1983, p. 51.

2 "Carta do Conde de Oeiras para o Conde da Cunha, 26/1/1765" in: Mendonça, Marcos Carneiro de. Século XVIII-Século Pombalino do Brasil, R. J.:Xerox do Brasil S.A., 1989, p. 426. ${ }^{3}$ Idem.

4 "Instrução do Conde de Oeiras ao Conde da Cunha, 20/6/1767" In: Marcos Carneiro de Mendonça, Século XVIII, op.cit., p. 463.

${ }^{5}$ Idem.

${ }^{6}$ Idem.

${ }^{7}$ Idem.

8 "Ofício do Vice-Rei Conde da Cunha para Francisco Xavier de Mendonça Furtado. Rio de Janeiro (RJ), 16/6/1764", Arquivo Histórico Ultramarino (AHU), Caixa (Cx.) 77, Documento (Doc.) 77.

${ }^{9}$ Idem.

10 "Ofício do Vice-Rei Conde da Cunha para Francisco Xavier de Mendonça Furtado. RJ, 10/7/1764”, AHU, Cx. 78, Doc. 4. 
11 "Ofício do Vice-Rei Conde da Cunha para Francisco Xavier de Mendonça Furtado, RJ. 16/6/1764”, AHU, Cx. 77, Doc. 77.

12 Idem

${ }^{13}$ Idem

14 "Ofício do Vice-Rei Conde da Cunha para Francisco Xavier de Mendonça Furtado. RJ, 23/9/1764”, AHU, Cx. 79, Doc. 24.

15 "Ofício do Vice-Rei Conde da Cunha para Francisco Xavier de Mendonça Furtado. RJ, 10/7/1764”, AHU, Cx. 78, Doc. 4.

${ }^{16}$ Idem.

${ }^{17}$ Idem.

${ }^{18}$ Idem.

${ }^{19}$ Idem.

20 "Ofício do Vice-Rei Conde da Cunha para Francisco Xavier de Mendonça Furtado. RJ, 23/9/1764”, AHU, Cx. 79, Doc. 24.

${ }^{21}$ Idem.

${ }^{22}$ Idem.

23 "Ofício do Vice-Rei Conde da Cunha para Francisco Xavier de Mendonça Furtado. RJ, 29/1/1765”, AHU, Cx. 80, Doc. 32.

24 "Ofício do Bispo do Rio de Janeiro, Frei Antonio do Desterro, para Francisco Xavier de Mendonça Furtado. RJ, 22/12/1766”, AHU, Cx. 86, Doc. 60.

25 Idem.

26 "Ofício do Provincial da Ordem de N. S. do Monte do Carmo do Rio de Janeiro, Frei Manoel Ângelo, para Francisco Xavier de Mendonça Furtado. RJ, 20/8/1764”, AHU, Cx. 78, Doc. 21.

${ }^{27}$ Idem.

${ }^{28}$ Idem.

${ }^{29}$ Carta do Vice-Rei Conde da Cunha ao Rei D. José I. RJ, 1/6/1764”, AHU, Cx. 77, Doc. 59.

${ }^{30}$ Idem.

${ }^{31}$ Idem.

${ }^{32}$ Idem.

${ }^{33}$ Carta do Vice-Rei Conde da Cunha ao Rei D. José I. RJ, 18/6/1764”AHU, Cx. 77, Doc. 86.

34 “Minuta escrita pelo Vice-Rei Conde da Cunha. RJ, 1767”, AHU, Cx. 90, Doc. 76.

35 "Ofício do Vice-Rei Conde da Cunha para Francisco Xavier de Mendonça Furtado RJ, 3/11/1765”, AHU, Cx. 83, Doc. 1.

${ }^{36}$ Idem. 
37 Santos, Corcino dos. O Rio de Janeiro e a Conjuntura Atlântica: Rio de Janeiro, Ed.Expressão e Cultura, 1993, p. 16.

38 "Minuta escrita pelo Vice-Rei Conde da Cunha. RJ, 1767”, AHU, Cx. 90, Doc. 76.

39 "Ofício do Vice-Rei Conde da Cunha para Francisco Xavier de Mendonça Furtado. RJ, 24/3/1767”, AHU, Cx. 87, Doc. 78.

40 "Ofício do Vice-Rei Conde da Cunha para Francisco Xavier de Mendonça Furtado. RJ, 23/9/1764”, AHU, Cx. 79, Doc. 24.

41 "Ofício do Vice-Rei Conde da Cunha para Francisco Xavier de Mendonça Furtado. RJ, 29/6/1765”, AHU, Cx. 81, Doc. 55.

${ }^{42}$ Idem.

43 "Edital, em que fez. Ordenar S.Mage. que todos os homens que se acharem vagabundos nos Sertoens, ou em Sítios Volantes desta Capitania, sejão logo obrigados a viverem em Povoações civis, Ajuda, 22/7/1766. ” Arquivo Nacional do Rio de Janeiro, Códice 73, vol. 2, p. 14 .

${ }^{44}$ Idem.

${ }^{45}$ Idem.

46 Idem.

${ }^{47}$ Idem.

${ }^{48}$ Idem.

${ }^{49}$ Idem.

${ }^{50}$ Idem.

51 “Carta do Vice-Rei Conde da Cunha ao Rei D. José I. RJ, 1/6/1764. ” AHU, RJ, Cx. 77, Doc. 58.

52 Idem.

${ }^{53}$ Idem.

${ }^{54}$ Idem.

${ }^{55}$ Idem.

56 “D.José para o Conde da Cunha, Lisboa, 15/12/1764”, AHU, Códice 230, p.131.

57 "Carta do Vice-Rei Conde da Cunha ao Rei D. José I. RJ, 1/6/1764”, AHU, RJ, Cx. 77, Doc. 58.

58 "Ofício do Vice-Rei a Francisco Xavier Mendonça de Furtado, RJ, 22/6/1765”, AHU, RJ, Avulsos, Cx.81, doc. 45.

59 “Ofício do Vice-Rei a Francisco Xavier de Mendonça Furtado. RJ, 23/2/1767”, AHU, RJ, Cx. 87, Doc. 37.

${ }^{60}$ Idem.

${ }^{61}$ Idem.

${ }^{62}$ Idem. 
63 “Ofício do Vice-Rei a Francisco Xavier Mendonça Furtado, RJ, 4/2/1767”, AHU, RJ, Avulsos, Cx.87, doc.24.

${ }^{64}$ Idem.

65 "Ofício do Vice-Rei a Francisco Xavier Mendonça Furtado, RJ, 17/8/1767", AHU, RJ, Avulsos, Cx.87, doc.7-g

66 "Ofício do Conde da Cunha para Francisco Xavier Mendonça Furtado, R.J., 17/9/1764", AHU, RJ, Avulsos, Cx.79, doc.11.

67 "Ofício do Conde da Cunha para Francisco Xavier Mendonça Furtado, R.J., 9/9/1767", AHU, RJ, Avulsos, Cx.89, doc.60.

68 "Ofício do Conde da Cunha para Francisco Xavier Mendonça Furtado, R.J., 15/3/1764", AHU, RJ, Avulsos, Cx.77, doc.38.

69 "Ofício do Conde da Cunha para Francisco Xavier Mendonça Furtado, R.J., 29/2/1764", AHU, RJ, Avulsos, Cx.77, doc.25

70 "Ofício do Conde da Cunha para Francisco Xavier Mendonça Furtado, R.J., 6/9/1766", AHU, RJ, Avulsos, Cx.86, doc.11.

71 "Ofício do Conde da Cunha para Francisco Xavier Mendonça Furtado, R.J., 17/9/1764", AHU, RJ, Avulsos, Cx.79, doc.11.

72 "Ofício do Conde da Cunha para Francisco Xavier Mendonça Furtado, R.J., 4/7/1765", AHU, RJ, Avulsos, Cx.82, doc.16.

73 "Ofício do Conde da Cunha para Francisco Xavier Mendonça Furtado, R.J., 17/9/1764", AHU, RJ, Avulsos, Cx.79, doc.11.

74 "Ofício do Conde da Cunha para Francisco Xavier Mendonça Furtado, R.J., 6/9/1766", AHU, RJ, Avulsos, Cx.86, doc.11.

75 "Ofício do Conde da Cunha para Francisco Xavier Mendonça Furtado, R.J., 1/11/1767", AHU, RJ, Avulsos, Cx.90, doc.2.

${ }^{76}$ Idem.

77 “Ofício do Conde da Cunha para Francisco Xavier Mendonça Furtado, R.J., 9/9/1767”, AHU, RJ, Avulsos, Cx.89, doc.60.

78 "Ofício do Conde da Cunha para Francisco Xavier Mendonça Furtado, R.J., 1/11/1767", AHU, RJ, Avulsos, Cx.90, doc.2.

79 “Ofício do Conde da Cunha para Francisco Xavier Mendonça Furtado, R.J., 9/9/1767", AHU, RJ, Avulsos, Cx.89, doc.60.

80 "Conde de Azambuja para Francisco Xavier Mendonça Furtado, R.J., 18/5/1768”, AHU, RJ, Avulsos, Cx.91, doc.67.

81 "Ofício do Vice-Rei Conde da Cunha para Francisco Xavier de Mendonça Furtado. RJ, 9/9/1767”, AHU, Cx. 89, Doc. 60.

82 "Requerimento do Capitão de Ordenança à pé de Itaboraí a D.José, RJ, 27/2/1765", AHU, RJ, Avulsos, Cx.80, doc.75. 
${ }^{83}$ Idem.

${ }^{84}$ Idem.

${ }^{85}$ Idem.

86 "Edital, em que fez. Ordenar S.Mage. que todos os homens que se acharem vagabundos nos Sertoens, ou em Sítios Volantes desta Capitania, sejão logo obrigados a viverem em Povoações civis, Ajuda, 22/7/1766. ” ANRJ, Códice. 73, vol. 2, pág. 14.

${ }^{87}$ Idem.

${ }^{88}$ Idem.

${ }^{89}$ Idem.

${ }^{90}$ Idem.

\section{Resumo}

O presente artigo tem por objetivo o estudo da situação militar da capital do Estado do Brasil, o Rio de Janeiro, durante a segunda metade do século XVIII. Ater-nos-emos mais especificamente ao período do governo do ViceRei Conde da Cunha (1763-1767), quando se iniciava o estabelecimento das novas diretrizes da Coroa portuguesa referentes à militarização da população colonial. Tais diretrizes, por suas intensas conseqüências sociais, acabaram por tornar esse período especialmente interessante devido ao impacto que produziu na sociedade.

Palavras-chave: corpos militares, recrutamento, deserção, fronteiras, sertão

\section{Abstract}

This article aims at studying the military situation of the capital of the State of Brazil - Rio de Janeiro -, during the second half of the 18th century. More specifically, we shall stick to the government of the Vice Roy Conde da Cunha (1763-1767), when the establishment of the new directives of the Portuguese Crown concerning the militarization of the colonial population was about to start. Such directives, due to their intense social consequences, ended up making such period become especially interesing due to their impact upon society.

Key Words: Military corps, draft, desertion, frontiers, inland. 